\title{
Study on Seat Capacity Allocation in Airline Alliance
}

\author{
Yingjing Gu, Jinfu Zhu \\ School of Transportation Management for Civil Aviation, Nanjing University of Aeronautics and \\ Astronautics, 29 Jiangjun Street ,Nanjing211106, Jiangsu, China \\ 535796430@qq.com
}

Keywords:Airline alliance; Seat capacity allocation; Stochastic programming

\begin{abstract}
In order to optimize seat capacity allocation in airline alliance, improve airline alliance revenue, we developed a stochastic programming model with the revenue of operating airlines as objective function, and used the EMSR method to solve it with MATLAB. The optimal allocations of seat capacity under the different transfer pricesare obtained so that the operating airlines wins maximized expected revenue and marketing airlines pays minimized transfer price. The result shows the model is feasible and effectively to maximize the revenue of the marketing airlines and promote the stability of airline alliance.
\end{abstract}

\section{1 . INTRODUCTION}

Since the 1990s, airlines are going to join alliances for increase the revenue by sharing the code and the network instead of fleet or network expansion. According to IATA in 2014, the three airline alliances had occupied a market share of $60.8 \%$, and airlines which have not joined any airline alliance are continuously strengthening cooperation with others. It is becoming increasingly important to use the revenue management in an alliance because sales of corporate itinerariesare growing.

Although, there are a lot of researches about revenue management, but little attention has been paid by an airline alliance. Vinod ${ }^{[1]}$ described and analyzed many of the cooperation mechanism in alliance and the research directions should be considered in the future, but he didn't provide an in-depth study of these methods. Graf and Kimms ${ }^{[2]}$ have developed the capacity control models based on real options for a two-airline alliance, but they didn't use the recall price in the concept of real options.Kimms and Çetiner ${ }^{[3]}$ as well as Çetiner and Kimms ${ }^{[4]}$ introduced procedures to sharing the revenue among the partners in fairways so that none of them has an incentive to leave the alliance, which are based on the nucleolus concept from cooperative game theory. At AGIFORS Cargo and Revenue Management Study Group meeting in Taipei ${ }^{[5]}$, the Operations Research experts provides a practitioner-oriented review of the problems, opportunities and best practices associated with codeshare and alliance revenue management base on roundtable discussions. Wright ${ }^{[6][7]}$ investigated revenue sharing issues that arise within an alliance.Hu et al. ${ }^{[8]}$ described the alliance operation as a two-stage game, he focused on revenue sharing mechanisms that lead to maximal revenue for the complete alliance and modeled the individual partners' decisions so that their models incorporated the central solution.

Above all, the existing researches centered on how to utilize revenue sharing to control seat inventory in an airline alliance and very little was involved in capacity allocation. The airlines in China joined alliance in recent years, and they don't know how to guarantee income increases by determining the number of seat capacity allocated to the marketing airlines at different transfer prices. In this paper, a stochastic programming model is established for the allocation of seat capacity in an airline alliance at different transfer prices. 


\section{2 . Stochastic Programming Method of Capacity Allocation in Airline Alliance 2 . 1 Statement on Seat Capacity Allocation in Airline Alliance}

In an airline alliance, it is generally the operating airlines and themarketing airlines who separately sell the tickets. The operating airlines refers to the airline actually provides flights, on the contrary, the marketing airlines only sells tickets but do not provide any flights. The latter pays the former the transfer price for using of seats. Considering the independence and maneuverability of system, currently airline alliances adopt fixed seat capacity allocation, which means operating airlines allocates fixed number of seats to marketing airlines while the marketing airlines pays transfer prices. The key to seat capacity allocation in airline alliance is to properly determine the number of capacity allocated at different transfer prices for two purposes: satisfying the marketing airline's demand and increasing its own profit.

In reality, airlines in alliance sell it's or others' tickets, so marketing airlines and operating airlines could exchange according the leg who operate.In this paper, we establishes a mathematical model of capacity allocation with stochastic programming and calculates stochastic passenger demand with the method of $\mathrm{EMSR}^{[9]}$. In our paper, the operating airlines could obtain the optimal number of allocation seats to guarantee its max profit with fixed transfer price. Moreover a seat capacity protection coefficient is added to ensure the passenger satisfaction of the operating airlines. In addition, the lowest transfer price paid by themarketing airlinescould be calculated when a fixed number of seats are required.

\section{2 . 2 Symbol Description and Hypotheses}

We consider the stochastic model in an alliance consisting of two partner airlines, and the operating airlines offers one flight with $C$ seats. In the flight, there are $n$ fare levels, $i \in\{1,2 \mathrm{~L} n\}$, $p_{i}$ refers to prices of the corresponding fares and $p_{1}>p_{2}>p_{3} \mathrm{~L}>p_{n} ; d_{i}$ refers to the passenger demands of the corresponding fares; $c_{i}$ to the number of seats allocated by operating airlines to the corresponding fares of all levels; $c_{S}$ refers to the number of seats allocated by the operating airlines to the marketing airlines in accordance with an agreement signed in airline alliance with a transfer price of $p_{s}$. Finally, $R$ refers to the revenue gained by the operating airlines.

Research assumptions of this paper are given on the following basis.

(1)Travelers' demand $d_{i}$ is a random variable of nonnegative integer and also obeys normal distribution: $d_{i}: N\left(\mu, \sigma^{2}\right)$ and mutual independence exists among $d_{i}$, and this is the general assumption in revenue management.

(2) Due to antitrust laws, information cannot completely be shared among airlines in airline alliance, so the operating airlines only know its own pares and travelers' demand.

(3) It is assumed that passengers who have seats reserved do not cancel them, and they are not No Show.

(4) The seats allocated to marketing airlines cannot be recalled, so it means the fixed allocation.

\section{2 . 3 Stochastic Programming Model}

During reservation, the actual number of reservation is $d_{i}$; if $c_{i} \geq d_{i}$, and it is $c_{i}$; if $c_{i}<d_{i}$, so the 
total revenue of operating airlines is

$$
R=c_{s} p_{s}+\sum_{i=1}^{n} p_{i} \min \left(d_{i}, c_{i}\right)
$$

Because $d_{i}$ is a random variable of nonnegative integer, so the expected revenue of operating airlinesunder the known distribution is

$$
E(\mathrm{R})=c_{s} p_{s}+p_{i} \sum_{i=1}^{n}\left[\int_{-\infty}^{c_{i}} x f(x) d x+c_{i} \int_{c_{i}}^{\infty} f(x) d x\right]
$$

In equation(2), $f(x)$ is the probability density function of $d_{i}$ (expressed in the formula with dummy variable $x$ ).

So the expected revenue of operating airlines could be described as

$$
\begin{gathered}
\max [E(\mathrm{R})] \\
\text { Subject to } c_{s}+\sum_{i=1} c_{i} \leq C \quad \text { (3) } \\
c_{s}, c_{i} \geq 0 \text {, and should be integers }
\end{gathered}
$$

The objective function (2) maximizes the revenue over all allocating classes of the operating airlines under the assumption $c_{s}$ is the number of seats which are allocated to the marketing airlines. Additionally, the sum of the allocating seats can't exceed to the total seat capacity on the leg (3). The allocating limits of the allocating seats should bepositive number and integers (4).

\section{3 . Allocating processes}

\section{3 . 1 Calculating process by EMSR}

According to the method of EMSR, we can get the process of calculating:

(1)When $p_{i+1}<p_{S}<p_{i}$, seats of $c_{i+1}$ should be allocated to the marketing airlines under the transfer price of $p_{S}$.

$r_{i+1}^{j}$ refers to the marginal revenue of any seat of one class and it can be expressed as follows

$$
r_{i+1}^{j}=p_{i+1} \times\left(1-\operatorname{prob}\left(d_{i+1}<j\right)\right)
$$

$r_{S}$ refers to the revenue acquired by theoperating airlines if one seat was allocated to the marketing airlines

$$
r_{S}=p_{S}
$$

$\operatorname{prob}\left(d_{i}<j\right) \geq 0$, so $1-\operatorname{prob}\left(d_{i}<j\right) \leq 1$. By $p_{i+1}<p_{S}$, therefore, $r_{i+1}^{j}<r_{S}$ can be set up permanently. In the case, if the seat is allocated to the marketing airlines, the total expected revenue of the operating airlines will increase.

(2) Similarly, when $p_{s}<p_{i}$, and $r_{i}^{j}<r_{s}$, the seat will be allocated to the marketing airlines. 


\section{3 . 2 Capacity protect of operating airlines}

The following problems arise in such a circumstance described above.

(1)If a high proportion of seats are allocated to marketing airlines, passengers of the operating airlines who would like to buy tickets at a low price are unable to obtain appropriate tickets as they expect. Over time, they will be dissatisfied.

(2)According to the regular pattern of ticket reservation, the longer from the departure time, the lower price tickets will be open to passengers. If the low price tickets have been allocated to marketing airlines entirely, ticket reservation period will be concentrated on a few days near the departure time, that is, it lies in the sales period of high-price tickets. Due to the randomness of passenger demands, the possibility of damages will be higherif tickets arefailing to be soldin time.

So, we set up the capacity protection coefficient for different fares of all levels at the time of performing seating allocations in airline alliance. If we assume theoperating airlines does not allocate seats to themarketing airlines, the allocation of seat inventory with all classes is denoted as $c_{i}$, while as $c_{i}^{\prime}$ after they are allocated to marketing airlines. Hence, we can obtain the following equation.

$$
\begin{gathered}
\max [E(R)] \text { (5) } E(\mathrm{R})=c_{s} p_{s}+p_{i} \sum_{i=1}^{n}\left[\int_{-\infty}^{c_{i}} x f(x) d x+c_{i} \int_{c_{i}}^{\infty} f(x) d x\right] \\
\text { Subject to } c_{s}+\sum_{i=1} c_{i}^{\prime} \leq C \quad \text { (7) } \\
c_{i}^{\prime} \geq \alpha_{i} c_{i} \text { (8) } \\
0 \leq \alpha_{i} \leq 1 \text { (9) } \\
c_{s}, c_{i}, c_{i}^{\prime} \geq 0 \text { and should be integers (10) }
\end{gathered}
$$

Equation (8) and (9) refer to the protection level for seat inventory of all classes from the operating airlines.

\section{Case Analysis}

It is assumed that an airline serves as the operating airlines of an airline alliance. There are 150 seats on a flight and they are divided in 6 classes. According to historical data, the fare level and passenger demands of fares can be seen in Table I .

TABLE I Fare and Demands

\begin{tabular}{ccccccc}
\hline Fare Level & $\mathrm{Y}(1)$ & $\mathrm{H}(2)$ & $\mathrm{M}(3)$ & $\mathrm{T}(4)$ & $\mathrm{E}(5)$ & $\mathrm{Q}(6)$ \\
$p_{i}$ & 1000 & 850 & 700 & 550 & 400 & 250 \\
$d_{i}$ & $(8,3)$ & $(20,5)$ & $(28,6)$ & $(36,7)$ & $(40,6)$ & $(45,8)$ \\
$\alpha_{i}$ & 1 & 0.9 & 0.8 & 0.7 & 0.6 & 0.5 \\
\hline
\end{tabular}

On condition that the company does not join the airline alliance, EMSR method can be adopted to work out allocations of seats with various classes as well as the expected revenue $\mathrm{R}$, as shown in 
Table II .

TABLE II Capacity allocation and total expect revenue under no alliance

\begin{tabular}{ccccccc} 
Fare Level & $\mathrm{Y}(1)$ & $\mathrm{H}(2)$ & $\mathrm{M}(3)$ & $\mathrm{T}(4)$ & $\mathrm{E}(5)$ & $\mathrm{Q}(6)$ \\
$c_{s}$ & 5 & 15 & 23 & 32 & 38 & 37 \\
$\mathrm{R}$ & 72961.85 & & & & & \\
\hline
\end{tabular}

By using of MATLAB programming, the optimal number of seats allocated by theoperating airlines to the marketing airlines can be figured out.In the airline alliance under different transfer prices the optimal seatsand interval of seats allocated have been determined together, as given in Table III.

TABLEIII Capacity allocation and total expect revenue under alliance without capacity protect

\begin{tabular}{ccccccc}
\multicolumn{1}{c}{$p_{s}$} & $C_{s}(\operatorname{Rmax})$ & $\operatorname{Rmax}$ & $c_{i}(1,2,3,4,5,6)$ & Interval \\
1 & 200 & 0 & 72961.85 & $(5,15,23,32,38,37)$ & $(0,0)$ \\
2 & 300 & 40 & 75071.11 & $(5,15,23,32,35,0)$ & $(0,71)$ \\
3 & 400 & 62 & 79391.18 & $(5,15,23,32,13,0)$ & $(0,120)$ \\
4 & 500 & 81 & 87190.91 & $(5,15,23,26,0,0)$ & $(0,150)$ \\
5 & 600 & 109 & 96798.12 & $(5,15,21,0,0,0)$ & $(0,150)$ \\
6 & 700 & 129 & 107994.86 & $(5,15,1,0,0,0)$ & $(0,150)$ \\
7 & 800 & 133 & 121146.12 & $(5,12,0,0,0,0)$ & $(0,150)$ \\
8 & 900 & 146 & 135228.43 & $(4,0,0,0,0,0)$ & $(0,150)$ \\
\hline
\end{tabular}

TABLE V Capacity allocation and total expect revenue under alliance under capacity protect

\begin{tabular}{ccccccc} 
& $p_{s}$ & $c_{s}$ & $(\operatorname{Rmax})$ & $\operatorname{Rmax}$ & $c_{i}(1,2,3,4,5,6)$ & Interval \\
1 & 200 & 0 & 72961.85 & $(5,15,23,32,38,37)$ & $(0,0)$ \\
2 & 300 & 21 & 74120.74 & $(5,15,23,32,35,19)$ & $(0,36)$ \\
3 & 400 & 34 & 76538.68 & $(5,15,23,32,23,19)$ & $(0,47)$ \\
4 & 500 & 39 & 80138.41 & $(5,15,23,27,23,19)$ & $(0,47)$ \\
5 & 600 & 42 & 84183.21 & $(5,15,21,25,23,19)$ & $(0,47)$ \\
6 & 700 & 45 & 88579 & $(5,15,18,25,23,19)$ & $(0,47)$ \\
7 & 800 & 47 & 93211.67 & $(5,13,18,25,23,19)$ & $(0,47)$ \\
8 & 900 & 47 & 93211.67 & $(5,13,18,25,23,19)$ & $(0,47)$ \\
\hline
\end{tabular}

In Table III\& $\mathrm{V}$, while $p_{s}$ refers to the transfer price, $c_{s}$ (Rmax) to the optimal number of seats which should be allocated to marketing airlines provided and the carrier airline is able to achieve the maximum expected revenue under the transfer price is determined; Rmax to the maximum expected revenue under the optimal $c_{s}, c_{i}$ to allocations of remaining seats in the operating airlines under this situation, and the expected revenue gained by theoperating airlines will increase when seats in the intervalallocated to marketing airlines at the confirming transfer price .

By calculations, the minimum transfer price paid by the marketing airlines can be achieved with the different numbers of allocated seats in the alliance agreement, in order that the total expected revenue gained by the operating airlines is no less than the revenue acquired if it operated alone, as shown in Figure 1. 


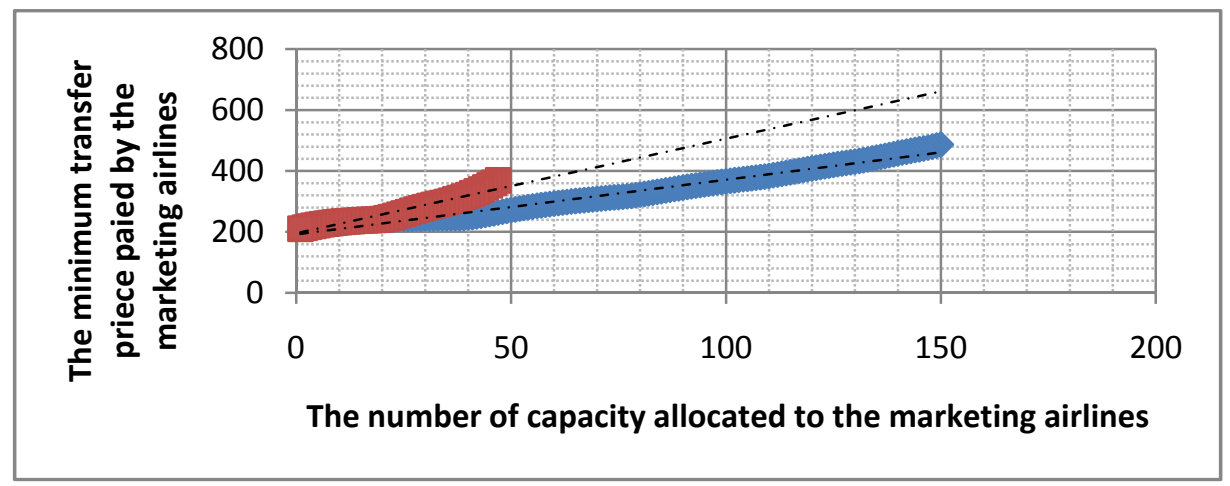

Fig.1 The number of allocation and transfer price

Note: Long full lines refer to unoccupied seat inventory protection, short full lines to occupied seat inventory protection, and the dotted lines to variation tendencies of transfer price with changes in the number of allocated seats.

By analysis of data above, following summaries can be drawn

1. If seat capacity allocation is carried out according to this model, revenues of the operating airlines can be improved, contributing to the stability and growth of the airline alliance;

2. Through capacity protection at each level of fares in the operating airlines, although the expected return is reduced, it can be ensured that the operating airline's market satisfaction will not reduce substantially, and the travel requirements of travelers atallclassescould be met. It is more suitable for practical operations;

3. It can be seen from Figure 1, with the increase of the number of seats allocated to marketing airlines, the minimum transfer price becomes higher and higher and even exhibits a trend of almost linear growth, which conforms to the market discipline. By comparing two lines, it is clear that the transfer priceswith seat capacity protection are higher, thereby partly increasing the payment cost of the marketing airlines.

\section{5 . Conclusions}

According to management rulesof airline alliance, a seat capacity control model for the operating airlines is established, and the EMSR method is employed to obtain solutions by MATLAB. The research results provided the optimal allocation of seat capacity in different transfer prices, so as to maximize the total expected revenue of the operating airlines.

In addition, seat capacity protection of the operating airlines is introduced which makes the model more practical and it plays animportant role in seat capacity allocations after airlines of China joinedthree airline alliances. Considering that the revenue management adopted by the majority airlines takes advantage of the EMSR theory at present, this model can be applied into the current revenue management system as it is easy for operations and provided practical effects. However, the seats allocated with the model in this paper can't be recalled by operating airlines and that can cause waste, so it should be the direction of future further studies.

\section{References}

[1] Vinod B., Alliance Revenue Management. Journal of Revenue and Pricing[J]. Management Science, 2005,4(1): 66-82.

[2] Graf, Mand A, Kimms.,Transfer price optimization for option-based airline alliance revenue management[J].International Journal of Production Economics,2013(9):281-293.

[3]Kimms, A and D, Çetiner., Approximate nucleolus-based revenue sharing in airline alliance[J]. European Journal of Operational Research, 2012(220):510-521.

[4]Çetiner, D and A, Kimms.,Assessing fairness of selfish revenue sharing mechanisms for airline alliances[J].Omega, 2013(8):641-652. 
[5]Ratliff,R andW,Larry., WeatherfordCodeshare and alliance revenue management best practices[C]. AGIFORS roundtable review, 2011.

[6]Wright C. P.,Dynamic Revenue Management in Airline Alliance[J].Transportation Science, 2010:15-37.

[7]Wright C. P., Decomposing Airline Alliance: A Bid-Price Approach to Revenue Management with Incomplete Information sharing[J]. Journal of Revenue and Pricing Management, 2014(3):164-182.

[8]Hu,X.,Caldentey,R and Vulcano,G., Revenue Sharing in Airline Alliance[J].Management Science,59(5):1177-1195.

[9]Peter P B., Air travel demand and airline seat inventory management[D].Massachusetts Institute of Technology, 1987. 